\title{
Device Incorrectly Disinfected/Sterilized During Reprocessing
}

National Cancer Institute

\section{Source}

National Cancer Institute. Device Incorrectly Disinfected/Sterilized During Reprocessing. NCI Thesaurus. Code C139487.

The disinfection/sterilization process was incorrect and/or the wrong products for disinfection/sterilization were used. 